\title{
Implicações para o serviço social no contexto da reconfiguração das políticas sociais
}

\author{
Implications for social work in the context of the reconfiguration of social policies
}

\author{
VALTER MARTINS (
}

Universidade Federal Fluminense (UFF), Campos dos Goytacazes, RJ, Brasil.

RESUMO - Este estudo tem como objetivo analisar as transformações da política social e as implicações para o assistente social no cenário atual. Para tanto, analisa-se as transformações recente na relação da política social com o Estado e os desafios para a profissão de Serviço Social. Os resultados indicam para um processo de redução do padrão protetivo das políticas sociais com o aprofundamento e modificação da agenda neoliberal, do qual implica substancialmente no trabalho desenvolvido por assistentes sociais, ao passo de atuarem com o processo de seletividade, focalização e mercantilização imposta às políticas sociais.

Palavras-chave: Serviço Social. Política Social. Trabalho. Focalização e Consumo.

ABSTRACT - This study aims to analyze the transformations of social policy and the implications for the work of the social worker in the current scenario. To that end, the recent transformations in the relationship between social policy and the State and the challenges to the Social Service profession are analyzed. The results indicate a process of reducing the protective pattern of social policies with the deepening and modification of the neoliberal agenda, which involves substantially the work developed by social workers, while acting with the process of selectivity, targeting and commodification imposed on policies social rights.

Keywords: Social Work. Social Policy. Work. Targeting and Consumption. 


\section{Introdução}

$\mathrm{O}$ presente texto tem como objetivo analisar as transformações da política social e as implicações para o trabalho do assistente social no cenário atual. O texto compõe parte dos esforços analíticos da pesquisa Mercado de Trabalho e Espaços Ocupacionais do Serviço Social nas regiões Norte e Noroeste Fluminense. ${ }^{1}$ Como ponto de partida, compreendemos que o trabalho do assistente social está pulverizado de práticas institucionais, ao considerarmos a "inscrição da profissão na divisão social e técnica do trabalho, compondo as respostas que o Estado e as classes dominantes constroem frente as expressões da questão social" (DEGENSZAJN, 2018, p. 155).

Tomando o desenvolvimento da profissão, nas respostas ao receituário neoliberal, ela vem tentando assegurar uma imagem profissional, na qual busca afirmar-se como uma profissão socialmente necessária, situada no âmbito da prestação de serviços sociais, previstos pelas políticas públicas sociais, que tem na Constituição de 1988 a ampliação de direitos sociais, cuja normatização abriu novas frentes para o trabalho profissional na área da Seguridade Social, no seu tripé saúde, previdência e assistência social, como áreas privilegiadas da atuação do Serviço Social (KOIKE et al., 1997). O respaldo técnico-operativo da profissão tem sido construído e sustentado por meio do incremente teórico-metodológico da profissão, construindo no cenário do final de século $\mathrm{XX}$, onde fração de assistentes sociais se vincularam às lutas das massas trabalhadoras, seja pela conquista ou pela ampliação de direitos de cidadania, ou para reivindicar direitos civis e políticos.

O caldo cultural de resistência proporcionou ao Serviço Social a construção de um projeto pautado na formação teórica e técnico-operativa. Com uma estruturação inscrita nos marcos dos processos coletivos, uma autoimagem da profissão, capaz de eleger valores que a legitimam socialmente, priorizando objetivos e funções, formulando requisitos para o seu exercício, prescrevendo normas para o comportamento dos profissionais e estabelecendo bases de relações com usuários de seus serviços, com outras profissões e instituições (NETTO, 2006).

A posição assumida pela profissão após a maturação do seu projeto profissional tem se esforçado para promover a ruptura com o ajustamento do indivíduo ao meio social e com práticas antidemocráticas. Além de conferir uma luta contínua de toda a categoria em superar posturas e realidades conservadoras reatualizadas com o neoliberalismo e presente nas relações entre Estado e sociedade civil. Esse processo não se dá alheio a uma transformação endógena da profissão, mas associa-se às inquietações e aos questionamentos do contexto político e social brasileiro, de modo a questionar seu objeto, seus objetivos e sua vinculação teóricometodológica. Isso possibilitou ao Serviço Social brasileiro se renovar e transformar a formação profissional e, também, o exercício dos profissionais.

Se evidencia no Serviço Social brasileiro, dada as suas particularidades ao eleger a questão social como objeto e tendo como pressuposto a interpelação em direção a ordem social, econômica e cultural imposta pelas formas correntes do sistema econômico (CARBALLEDA, 2019), um leque de espaços ocupacionais demarcados pelas transformações da sociedade próprias dos avanços e alterações cíclicas do sistema econômico. Elas aprofundam as manifestações da questão social e a degradação do trabalho, ao qual o modo de produção está constantemente se expandindo a novas áreas de trabalho, inclusive moldandoas com os avanços tecnológicos, sendo continuamente requintado o aperfeiçoamento, de maneira que sua pressão sobre trabalhadores é incessante (BRAVERMAN, 1980). Além das particularidades de cada instituição empregadora, de forma que a profissão, em seu exercício, não detém uma regularidade de ações e instrumentos que atendam a todas as especificidades do trabalho, mas que desenvolve a sua dimensão técnico-operativa de acordo com as demandas e as condições institucionais, norteando-se por um projeto de profissão com bases teórico-metodológico e ético-político sustentado pelas Diretrizes Curriculares do Curso de Serviço Social e regulamentado pelas Leis $8662 / 93$ e 12.317/10 e pelas Resoluções CFESS 273/93, 290/94, 293/94, 333/96 e 594/11 (BRASIL, 2012).

A contrarreforma do Estado brasileiro processa-se com a revisão das políticas sociais, com a diminuição do tamanho do Estado e com a transformação da política econômica, deixando a política social ao cabo da econômica (BEHERING, 2008). Sendo as políticas que compõem a Seguridade Social operadas 
majoritariamente pelas instituições, os assistentes sociais têm, no aparelho estatal, campo expressivo da sua venda da força de trabalho, "cujo valor é estabelecido como qualquer outra mercadoria" (DEGENSZAJN, 2018, p. 155). Nesse turbilhão, há um conjunto de mudanças operadas no âmbito do Estado, especialmente a partir da década de 1990, sob a premissa das políticas neoliberais que transformaram a relação dos profissionais com as políticas sociais.

A partir das transformações no interior da máquina estatal, com as orientações de agências internacionais sobre as políticas sociais, tivemos a reconfiguração de um padrão de proteção social, no qual as políticas sociais, antes subscritas sob a premissa da universalização pública e pautadas no direito de cidadania, sofreram ataques e passaram a ser gestadas por uma nova lógica. A inovação ficou a cargo da substituição das políticas universalizantes por outras focalizadas em grupos vulneráveis, com alto grau de seletividade, associando a política social a uma racionalização dos gastos como nos setores lucrativos. A lógica de investimento social é usurpada por uma mercadológica sustentada sob a ótica do gasto do Estado.

Esse cenário implicou um conjunto de novas demandas operacionais para os assistentes sociais no seio na máquina estatal. Sendo que, o assistente social, em seu exercício, necessita dominar conteúdos específicos e gerais que contemplem respostas à realidade imediata, mas, também, respostas coletivas (SOUZA; AZEREDO, 2004), associadas às competências profissionais, pauta da categoria profissional desde o XXIX Encontro Nacional CFESS/CRESS (2000). Durante o evento foi deliberado pela construção do documento "Convite à Reflexão", primando pelo debate para a questão das atribuições privativas do assistente social, considerando as determinações do mercado de trabalho profissional e do corpo institucional empregador ${ }^{2}$, no contexto do desmonte das políticas sociais e do Estado.

O documento, dos anos 2000, manifestou preocupação com as dimensões da competência do profissional. Além disso, compreende que o Serviço Social, como profissão requisitada para responder às demandas da classe trabalhadora, concernente às expressões da questão social, depara-se cotidianamente com um conjunto crescente de novos espaços institucionais e novas demandas, ambos caracterizados, em especial, pelas transformações no modo de produção que agravam situações de pobreza ou criam novas manifestações decorrentes da complexa estrutura social instaurada pelas políticas neoliberalizantes.

O trabalho desenvolvido por assistentes socais, abarca o desenvolvimento de respostas às demandas em cada contexto temporal distinto, cada qual, a depender do grau de complexidade, dos recursos teóricos, das forças políticas e do desenvolvimento das forças produtivas, que promove um conjunto de práticas. O profissional não fica alheio à sua época. A preocupação, portanto, pauta-se na questão em que os assistentes sociais são, por competência, os operadores e os gestores de políticas sociais. Sendo assim, dadas as transformações nas políticas sociais que rapidamente têm absorvido o trabalho miúdo do cotidiano, efetivando as determinações neoliberais sob o prisma da hierarquia político-institucional e da políticainstrumental, operando um conjunto de políticas cada vez mais focalizadas e seletivas aos que "fracassaram no mercado de trabalho".

Contudo, essa direção não corresponde ao pressuposto afirmado nas diretrizes curriculares, quando preconizam a necessidade de um "rigoroso trato teórico, histórico e metodológico da realidade social e do Serviço Social [...], a compreensão dos problemas e desafios com os quais o profissional se defronta no universo da produção e reprodução da vida social", necessária "à apreensão da totalidade social em suas dimensões de universalidade, particularidade e singularidade" (ABEPSS, 1999).

\section{O limiar entre trabalho profissional e política social no final de século XX}

Em relação a algumas características do trabalho profissional, o assistente social, na esfera estatal, paraestatal ou privada, trabalha com planejamento, operacionalização e viabilização dos serviços sociais à população. Tradicionalmente, ele é convocado a agir na linha de frente das relações entre instituições e usuários, com certo poder de selecionar entre aqueles que têm ou "não" o direito de ser atendidos, criando uma fronteira que divide os elegíveis dos inelegíveis, normalmente devido aos cortes orçamentários destinados às políticas sociais. O cumprimento dessa função não tem tanta rigidez já que o profissional tem 
relativa autonomia de verificar condicionantes que podem ser traduzidos em agravante de determinadas situações de vulnerabilidade ou risco social.

Tal perspectiva é produto de uma construção histórica, na qual a profissão se reformulou, questionou suas bases teóricas e de atuação, rescindiu com todo um trabalho profissional que não possibilitava o rompimento com o sistema de dominação imposto pelo capitalismo, mas sua afirmação. Durante a transformação da profissão no Brasil, ela tem sido desafiada, principalmente entre os anos recentes, ao não se dissociar das mudanças da sociedade na busca por novas práticas comprometidas com a equidade, com a justiça social e com os preceitos democráticos, etc., sem desconsiderar as adversidades postas pela lógica da produção econômica e seus interesses corporativos.

O sistema econômico opera um conjunto de ajustes fiscais, implicando severas alterações nas relações entre Estado e sociedade, com reflexos para as políticas sociais e para o trabalho do assistente social. Isso se verifica no transcorrer da contrarreforma do estado brasileiro, ao se reconfigurar para manter o ritmo de produção, circulação e consumo, a fim de garantir a extração da mais-valia e não permitir a redução (ou recuperação) da taxa real de lucro (NETTO; BRAZ, 2006).

Dentre as mudanças mais substanciais está a refutação do desenho do Estado ampliado ${ }^{3}$ e a reconfiguração de seu papel provoca significativos impactos na política social e no modelo de proteção social. Desse modo, nos anos de 1990, sob a reação burguesa à crise do capital iniciada nos anos 70 , amplia-se o desmonte dos direitos sociais, suportes da política social, o aprofundamento e a visibilidade das contradições ${ }^{4}$ do capitalismo e as suas formas de barbarizarão da vida social.

Esse processo é disseminado pela forte influência do Banco Internacional para Reconstrução e Desenvolvimento (BIRD) nas propostas de "inclusão" e de uma concepção de política social direcionada ao indivíduo como célula potencializadora de transformação. Recorre à teoria do capital humano para desenvolver desenhos de políticas, principalmente de renda mínima associadas à educação e à saúde, com vistas a garantir a superação da situação de vulnerabilidade do indivíduo e das gerações futuras.

Dessa forma, o enfrentamento das expressões da questão social deu-se dentro do modelo histórico da realidade brasileira. Ou seja, por meio de uma política social de cunho corporativo associada aos antigos mecanismos da caridade e da filantropia voltada para certas situações de pobreza, distantes de um modelo de política social ancorado na afirmação de direitos sociais de cidadania (CARDOSO JR; JACCOUD, 2005).

No cenário brasileiro em que os direitos sociais foram positivados com a Constituição de 1988, enquanto a América Latina já sofria uma intensificação das diretrizes neoliberais impostas aos governos da região e disseminadas pelo denominado "Consenso de Washington". Os indicativos do Consenso propuseram a redução do déficit público e das funções estatais por meio de um controle monetário estrito e com um intenso processo de privatização dos ativos estatais (BATISTA, 1995).

Assim, em outros termos, a consolidação da democracia no Brasil, ao mesmo tempo em que reconheceu direitos sociais e de cidadania, gerando uma nova institucionalidade democrática, foi, também, um processo de redução do papel do Estado e da sua capacidade de investimento e de redistribuição às frações mais empobrecidas. As significativas mudanças ocorridas na política social dirigiram-se na descentralização dos programas e projetos de caráter social, participação da comunidade, adoção de um novo modelo de assistência social, implantação de programas e projetos autossustentáveis, parcerias, implantação de programas do tipo renda mínima, bolsa-escola e filantropia empresarial, além de um exército de voluntários (KAMEYAMA, 2000).

Esses contornos impressos à política social no Governo Fernando Henrique Cardoso são reproduzidos no Governo Lula, a partir de 2003. Mesmo sob novo discurso, a política social continuou submetida à política econômica, ainda que houvesse a criação, em 2004, do Ministério de Desenvolvimento Social e Combate à Fome (MDS) e com as ações desse ministério estruturadas em três grandes linhas (SIMIONATTO, 2008).

A primeira, com a Política Nacional de Assistência Social focada no desenvolvimento de programas de proteção social em dois níveis: a) proteção social básica voltada à socialização da família e do indivíduo com programas de Atenção Integral à Família, Agente Jovem e Benefício de Prestação Continuada; b) proteção social especial - desenvolvimento de ações de orientação e apoio sócio familiar. Na segunda, a Política Nacional de Segurança Alimentar e Nutricional, com o Programa Acesso à Alimentação, que envolveu e ainda 
envolve uma série de ações desenvolvidas nos estados e municípios que, em 2006, ganhou novo impulso com a aprovação da Lei Orgânica da Segurança Alimentar. E, na terceira, a ênfase nos programas de renda mínima, com destaque em reformulações e unificações de programas criados no governo de Fernando Henrique Cardoso (SIMIONATTO, 2008).

O profundo descaso com a política social entre os anos de 1995-2001, no governo do presidente Fernando Henrique Cardoso (primeiro mandato 1995-98, segundo mandato 1999-2002), leva, em 2001, a uma manobra para reverter a conjuntura do período, com a proposição de criação de uma "rede de proteção social", cujo carro chefe são os programas de renda mínima às famílias pobres considerando projetos já desenvolvidos por alguns municípios e estados (SILVA; YAZBEK; DI GIOVANNI, 2004). No modelo de enfrentamento das expressões da questão social, a política social realiza-se por meio de mecanismo de focalização apoiada em medidas pontuais em certas situações de pobreza, distante de um exemplo de política social fundada na afirmação de direitos sociais de cidadania (CARDOSO JR; JACCOUD, 2005).

\section{A fronteira porosa entre o velho e o novo projeto para as políticas sociais}

Os programas dirigidos à "inclusão social" e à redistribuição da renda apresentam-se como "absoluta prioridade do Governo Federal" a partir de 2003, e "o social" é tomado como "o eixo do projeto de desenvolvimento". Essa opção é justificada pelas seguintes razões: 1) "porque promovem justiça social e ampliam o atendimento aos direitos fundamentais da cidadania"; 2 ) "aumentam a eficiência da força de trabalho"; e 3) "fortalecem o aumento de produtividade e competitividade por meio do modelo de consumo de massa".

O aumento das taxas de crescimento figura, no plano, como um "elemento central para a inclusão social e a redistribuição de renda", pois favorece a criação de empregos, "via básica de inclusão". A promoção da "justiça social, a inclusão e a redistribuição da renda" apresentam-se como metas a serem "tenazmente perseguidas, independentemente do ritmo de crescimento que venha a se realizar". Soma-se a esse princípio a necessidade de "firme decisão política", uma vez que o crescimento, por si só, "não promove de forma adequada a inclusão social e, muito menos, permite avanços na distribuição de renda" (BRASIL, 2003).

Ao se reportar a realidade brasileira, Werneck Vianna (2008) aponta o paradoxo entre universalismo idealizado e a Constituição Federal de 1988, com as novas práticas pautadas na focalização e no consumo como desenho apropriado para as políticas sociais ${ }^{5}$. Para a autora o novo modelo apresenta-se como uma forma de contingenciar parte dos trabalhadores excedentes, para possibilitar, a recomposição da taxa de lucro do capital. Contudo, a autora aponta que essa controvérsia não se

resume a escolhas que governantes fazem diante de recursos finitos e demandas infindáveis no contexto atual. Também não traduz apenas posições divergentes em um aspecto ideológico cada vez mais confuso. Fundamenta-se, outrossim, em concepções teóricas distintas acerca da natureza e do papel das políticas sociais nas sociedades modernas (WERNECK VIANNA, 2008, p. 2).

Tal proposição tem apresentado um conjunto de demandas para o Serviço Social, ao mesmo tempo em que determina a forma de atenção a essa demanda. O neoliberalismo, que tensionou o Estado e transformou as políticas sociais, após duas décadas e meia, tem apresentado resultados no seio da estrutura social que intenta contra toda a construção do modelo de proteção social brasileiro e contra o projeto da profissão.

Esse cenário abarca um conjunto de transformações no mundo da produção, do Estado e das políticas públicas, estabelecendo novas mediações para as expressões da questão social, convertidas em demandas para o Serviço Social. O contexto das transformações atravessa o cotidiano do espaço profissional do assistente social, afetando suas condições e relações de trabalho, seu trabalho profissional, bem como as condições de vida da população usuária dos serviços sociais (IAMAMOTO, 2006).

As transformações apresentam-se em vários setores, em particular nas políticas sociais assume-se uma nova roupagem, pregando a ideia da igualdade e pressupondo uma solução conciliadora. Entretanto, essa concepção é percebida como mecanismo para promover oportunidades para todos. 
O aspecto presente na proposta apreende o Estado como regulador das forças ou garantidor do vigor do mercado, fonte de iguais oportunidades. Todavia, algumas ações serão aceitas como precípuas a esse papel "ações negativas, destinadas a não permitir que encargos trabalhistas onerem (ou desestimulem) as atividades empresariais, e ações positivas, como as que proporcionam educação (ou saúde) gratuita àqueles que se encontram em situação precária", propondo, assim, incrementar a igualdade de oportunidades (WERNECK VIANNA, 2008, p. 6).

Nessa quadra histórica, lamamoto (2006, p. 20) sinalizou que um dos desafios que o profissional enfrenta, sob a perspectiva apontada para as políticas sociais, é "desenvolver sua capacidade de decifrar a realidade e construir propostas de trabalho criativas e capazes de preservar e efetivar direitos, a partir de demandas emergentes no cotidiano". Rompendo com a lógica do mercado, ou seja, com a ideia de conciliar a política social como fomentadora de oportunidades, meramente via a focalização e o consumo.

Para responder às demandas, o assistente social, como trabalhador que possui capacidades e competências, precisa romper com atividades burocráticas do dia a dia, com as amarras da políticainstitucional atravessada por interesses coorporativos e pela dimensão da política-instrumental ditada pelas políticas sociais, e apreender as novas determinações e fomentar seu enfrentamento. $O$ trabalho do profissional pauta-se em um "sujeito profissional que tem competências para propor, para negociar com a instituição seus projetos, para defender o seu campo de trabalho, suas qualificações e funções" (IAMAMOTO, 2006, p. 21).

Porém, a conjuntura atual, com as transformações operadas nos últimos anos, parece condicionar a profissão a atividades meramente burocráticas de verificação de situações, imprimindo um reducionismo às competências profissionais e ajustando os espaços ocupacionais à verificação e alimentação de sistemas de processamento de informações. Dessa forma, restringe as capacidades de diagnosticar e propor a meras rotinas engessadas que dispensam conhecimentos adquiridos por uma formação de nível superior. A particularidade é condicionada, em certa medida, devido ao assistente social ser um profissional assalariado, precisando vender sua força de trabalho para instituições estatais, paraestatais e ou empresariais, o que torna o seu trabalho uma mercadoria (DEGENSZAJN, 2018).

Mesmo sob uma rápida recuperação econômica e a projeção do Brasil no cenário internacional, no período de governo do Partido dos Trabalhadores o referido contexto tem se agravado por causa dos acordos com agências multilaterais que favorecem a dinâmica da política econômica vigente da ação do governo brasileiro em priorizar os interesses do capital em detrimento dos interesses nacionais de superar o profundo fosso que separa os pobres de um padrão de cidadania. Suscitam daí as privatizações ainda em andamento, a manutenção do ajuste fiscal, a política monetária, os interesses decorrentes do pagamento das dívidas interna e externa, a flexibilização dos direitos trabalhistas e o sucateamento das políticas sociais. Em especial criando políticas sob o prisma da focalização e consumo, percebendo o acesso a um pseudo mercado como efetivação de cidadania. Inscreve-se neste cenário a marcha dos desmontes, especialmente com reforma trabalhista, criticada inclusive pela Organização Internacional do Trabalho (OIT), ou pela Emenda Constitucional 95 que congelou os gastos públicos por 20 anos, inviabilizando o orçamento para materialização das políticas que compõem a Seguridade Social.

As consequências geradas por esse quadro têm implicações severas em alguns extratos da classe trabalhadora que se veem diante do crescimento do desemprego, do aumento da precarização das condições de trabalho, no aumento do trabalho informal, da diminuição dos salários e direitos sociais e da ampliação do trabalho infantil. Mesmo que o governo tenha propagandeado que durante os governos do Partido dos Trabalhares houve o aumento do investimento com políticas sociais ele não acompanhou a lucratividade do capital, para o qual tem sido funcional, fazendo com que as pessoas se compreendam como cidadãs, quando da possibilidade de consumir, relacionando os direitos de cidadania ao mero acesso ao mercado de consumo.

Esse panorama desconstruiu as concepções mais progressistas das políticas sociais que, de acordo com Yazbek (2008, p. 6), devem permitir aos "cidadãos acessar recursos, bens e serviços sociais necessários, sob múltiplos aspectos e dimensões da vida", ou seja, "devem estar voltadas para a realização de direitos, necessidades e potencialidades dos cidadãos de um Estado". 
A desconstrução tem imprimido desde então um novo desenho de política social pautada no consumo com base na verificação e em rotinas burocratizadas, segundo Werneck Vianna $(2008$, p. 8), em sua crítica, a "nova" política social rompe com os direitos substantivos e universais, tal direção "obsta a liberdade, reduz o livre-arbítrio, produzindo uma falsa (ou ameaçadora) igualdade". A política social, portanto, deve ser produzida como alívio ou compensação pelos prejuízos que a desigualdade, inevitavelmente, causa a alguns. Isto é, focalizada, por exemplo, na saúde pública para os pobres, medidas assistenciais com alvos delimitados em grupos de risco, como tantas outras que se projetam para os próximos anos.

Esses aportes, em particular na periferia capitalista, estão "estruturalmente condicionados pelas características políticas e econômicas do Estado" e das contradições que decorrem do processo de acumulação. Assim, o reordenamento do capitalismo, nos últimos anos, além de desencadear um processo de desregulamentação dos direitos universais, substituindo-os por políticas focalizadas e compensatórias, acentuando a desigualdade, leva a um inevitável aumento do ciclo de pauperização e da ruptura com a universalização da proteção social (YAZBEK (2008, p. 4).

Contudo, para a autora, combater a pobreza fora da concepção dos direitos e da cidadania é abrir espaço para a "gestão da pobreza", não passando de ação técnica, de medida burocrática, de mobilização controlada ou de controle da política (YAZBEK, 2008). Nesse cenário, os assistentes sociais lidam diretamente com os efeitos do neoliberalismo e da reestruturação produtiva, em consequência de atuarem na execução das políticas sociais, como especialidade do trabalho coletivo na sociedade capitalista.

Diante disso, a transição do capital afeta o trabalho do profissional, considerando que o quadro sócio histórico não se reduz a um pano de fundo para que se possa discutir o trabalho social. Ele atravessa e conforma o cotidiano profissional do assistente social, afetando suas condições de trabalho e suas relações laborais, assim como as condições de vida da população usuária (IAMAMOTO, 2006). Com isso, o Serviço Social, como componente da organização coletiva do trabalho assalariado, tem suas condições e relações de trabalho alteradas pelas transformações sociais oriundas da fase da reestruturação do capital. Como também suas respostas às demandas tradicionais.

O modelo neoliberal promove o crescimento da exclusão e a despolitização da questão da pobreza, sendo que as propostas neoliberais, em relação ao papel do Estado, na esfera da proteção social, são propostas reducionistas, onde a assistência ao cidadão passa a ser para situações extremas, portanto, com alto grau de seletividade, e direcionada aos estritamente mais pobres. A perspectiva imprime um modelo de política social residual, apenas para complementar o que não se conseguiu via mercado.

As produções que problematizam a questão da informação para as políticas de Seguridade Social como avanço para se garantir direitos têm demonstrado, na cena atual, um cenário contraditório. A leitura da realidade e as novas tecnologias, algumas diretamente ligadas ao cotidiano do assistente social, têm revelado situação inversa. Pois, o que se percebe é o uso das tecnologias de informação para o aprofundamento de políticas residuais com alto grau de seletividade e focalização, como é o caso do Programa Bolsa Família, operado por lógicas aritméticas que dispensam o trabalho especializado na sua operacionalização, inclusive o do assistente social, uma vez que o Programa concebe o controle da frequência escolar, do uso dos equipamentos locais de saúde por qualquer sujeito que possa operar um sistema informacional, e, de forma mais incisiva, o grande responsável pela elegibilidade é o corte de renda per capita.

Werneck Vianna $(2008$, p. 8) afirma que esse preceito inaugurado na política social afirmativa de uma cidadania pautada na igualdade de oportunidades é um dissenso, pois "a cidadania não pode ser produzida e distribuída como vestimenta para cobrir indivíduos desnudos pela precariedade".

A concepção liberal revisitada postula a coexistência de políticas semiuniversais (educação básica e saúde para os pobres) e políticas focalizadas, apontando como objetivo primordial da ação pública a ampliação das oportunidades para que todos possam caminhar pelas próprias pernas. No Brasil, é preocupante a ausência de alternativas frente a proposição de novas propostas, como se a controvérsia entre universalização e focalização estivesse superada, apreendendo a política social como política para os pobres, no assistencialismo, caracterizado por transferência de renda com condicionalidades aos pobres, ou, ainda, mais recentemente, com a concessão de voucher a esses. 
O desempenho predominante da política social sob a forma do assistencialismo condicionado articula três dimensões: promoção do alívio imediato da pobreza, reforço ao exercício de direitos sociais básicos nas áreas de educação e saúde e a coordenação de programas complementares (BRASIL, 2018). Esse modelo tem característica intrínseca ao mercado e define a pobreza como a situação em que indivíduos se encontram por falta de capacidade de concorrerem no mercado e, portanto, vencerem no mundo competitivo.

A premissa da "nova" "política social (assistencialistas) para os pobres, ao exigirem condicionalidades e contrapartidas, funcionam como mecanismo de empoderamento, isto é, ensejam a aquisição de dotes necessários ao exercício das escolhas" (WERNECK VIANNA, 2008, p. 18), mediante a promoção do alívio imediato da pobreza e o reforço ao exercício de direitos sociais básicos nas áreas de saúde e educação, o que contribui para que as famílias consigam romper o ciclo da pobreza geracional, mas não a pobreza relativa. Contudo, nas marcas dos governos de Michel Temer/Jair Bolsonaro, a política social não possibilita nem a superação da pobreza absoluta, mas, tão somente, o aprofundamento das expressões de pobreza, fruto do desemprego em massa, da reforma trabalhista e de tantas outras iniciativas em prol do capital, em detrimento de uma concepção de cidadania plena.

Para os assistentes sociais, portanto, em seu trabalho cotidiano, é imprescindível problematizar sua inserção em espaços que não permitem a efetivação de políticas sociais pautadas no direito de cidadania progressista. Mas, àqueles que transformam a política social em mecanismo de acesso ao consumo e à liberdade do mercado, retomando o modelo de Walfare liberal, tratado por Anderson (1995), com políticas focalizadas, mínimas aos comprovadamente pobres. Yazbek (2008, p. 9) apresenta essa reconfiguração do padrão de regulação sócio-estatal no Brasil, no qual a intervenção do Estado prevalece sob as "políticas de inserção focalizadas e seletivas para as populações mais pobres (os invalidados pela conjuntura), em detrimento de políticas universalizadas para todos os cidadãos".

Diante de tal cenário, importa compreender os programas de transferência de renda como expressão máxima dessa tendência para as políticas sociais, onde temos um forte controle pautado na renda per capita como mecanismo de seletividade. A operacionalização desse modelo de programa tem forte presença dos assistentes sociais, seja na coordenação, na gestão ou na operacionalização pormenorizada das rotinas, apresentando-se como componente metamorfoseado do trabalho intelectual do profissional nas políticas sociais, uma vez que é reduzido a operador dos manuais, na efetivação de uma política-instrumental.

O assistente social tem trabalhado no limiar, onde precisa lidar com as contradições de efetivar direitos sociais via políticas, ao mesmo tempo em que é obrigado a submeter seu saber técnico às rotinas de um sistema informacional e aos critérios pré-estabelecidos no sistema e na política-instrumental. Temos, portanto, um exemplo drástico das implicações do novo modelo de política social, pautado na máxima da focalização e do consumo imposto aos profissionais. Esse modelo, do qual os programas de transferência de renda são precursores e protagonistas, se espraia para outras políticas e setores da vida, especialmente ao sequestrar o tempo do não trabalho, do lazer e do repousou com as novas tecnologias instantâneas.

Associado à manutenção do capitalismo para garantir níveis de acumulação, operam-se transformações tecnológicas que imprimem uma nova forma de gerir o trabalho, diminuindo a demanda por mão-de-obra. Aumenta-se, com isso, a população excedente, pauperizada e excluída simultaneamente que as forças produtivas e a própria produção avançam.

\section{Considerações finais}

O processo de globalização das economias e do livre mercado tem apresentado novas facetas das expressões de pobreza, de emprego precário, do subemprego, do emprego desprotegido dentre tantos outros fenômenos que assolam os países em desenvolvimento e materializam a questão social. Nesse liame, o Serviço Social brasileiro tem se deparado com um conjunto de desafios, tanto no deciframento da realidade, como, também, na formulação de respostas à onda de redução, seletividade e mercantilização imposta às políticas sociais. 
Em prol do mercado, a contenção de gastos tem sido voltada à geração do superávit primário, como propósito de assegurar as finanças dos credores da dívida pública (IAMAMOTO, 2018), promovendo o corte de recursos para as políticas sociais, consequentemente, criando mecanismos de redução do acesso aos direitos, especialmente com os mecanismos de focalização e seletividade. Nesse processo, os assistentes sociais têm sofrido as consequências das transformações em movimento, tanto como profissionais que utilizam as políticas sociais como ferramenta de trabalho, como sujeitos pertencentes da classe trabalhadora.

A lógica neoliberal, como mecanismo homogeneizador do fazer e das respostas, tem sequestrado o trabalho e transforma setores da profissão, contingenciando profissionais com restrições em suas formações, amputando possibilidades de formação continuada, impondo rotinas e respostas formuladas fora dos círculos técnicos e teóricos da profissão, impondo um trabalho penoso e rotineiro, atendendo a um número exorbitante de usuários, preocupado com o fazer imposto. Esses fatores têm conduzido a constituição de um novo perfil profissional, com novas respostas, novos contornos restritivos ao trabalho propositivo, criativo e vivo, e tem criado um trabalhador submetido as rotinas da política-instrumental.

Ao mesmo tempo, as condições de trabalho são alteradas em qualidade e substância. A incorporação de uma burocracia informacional, das determinações das políticas e das instituições tem capturado o profissional e o transformado num típico trabalhor da burocracia dos serviços. Com isso, perde-se a dimensão da vida das ruas, das associações, da organização ou da possibilidade de organizar a população para, juntos, contingenciar demandas e buscar incluir temas na agenda política que vá além daquelas determinadas ou das expressões mais marcantes da pobreza. $\mathrm{O}$ assistente social, por si, já é um recurso que vem sendo descaracterizado, recomposto à nova lógica do "cidadão consumidor".

Os recursos teóricos vêm sendo diminuídos no dia a dia, não se expressam mais em atos profissionais e têm ficado restritos ao discurso ideológico. A nova lógica do trabalho tem engolido a dimensão referida do trabalho vivo e dinâmico. $\mathrm{O}$ atender, o fazer mecânico, ganham dimensões mais amplas do que como pensar o fazer, como pensar as estratégias para e como fazer e de onde partir e onde se pretende chegar, sem, contudo, que esteja no discurso oficioso que só é possível em outra sociedade. Nesse cenário, as competências e atribuições profissionais têm perdido espaço para o imposto, para o mecânico, para a robotização.

\section{Referências}

ANDERSON, P. Balanço Neoliberal. In: SADER, E.; GENTILI, P (org.). Pós-neoliberalismo: as políticas sociais e o Estado democrático. Rio de Janeiro: Paz e Terra, 1995.

ABEPSS, Associação Brasileira de Ensino e Pesquisa em Serviço Social. Diretrizes Gerais para o curso de Serviço Social. Rio de Janeiro: ABEPSS, 1999.

ANTUNES, R. Os sentidos do trabalho: ensaio sobre a afirmação e a negação do trabalho. 2. ed. São Paulo: Boitempo, 2009.

BATISTA, P. N. O Consenso de Washington: A visão neoliberal dos problemas Latino-Americanos. Coleção Caderno Dívida Externa. São Paulo: Peres, 1995.

BEHERING, E. R. O Brasil em contra-reforma: destruição do Estado e perda de direitos. 2. ed. São Paulo: Cortez, 2008.

BIELSCHOWSKY, R. A evolução do pensamento da CEPAL: 1948-2008. Brasília, DF: FUNAG/IPRI, 2009.

BRASIL. Código de ética do/a assistente social. Lei 8.662/93 de regulamentação da profissão. 10. ed. Brasília, DF: Conselho Federal de Serviço Social, 2012.

BRASIL. Ministério do Desenvolvimento Social e Combate à Fome. Programa Bolsa Família [online]. Brasília, DF: Ministério do Desenvolvimento Social e Combate à fome. Disponível em: http://www.mds.gov.br/bolsafamilia/. Acesso em: 12 de out. 2018. 
BRASIL. Plano Brasil de Todos Participação e Inclusão - Orientação Estratégica de Governo: Crescimento Sustentável, Emprego e Inclusão Social. Brasília, DF, maio, 2003.

BRAVERMAN, H. Trabalho e capital monopolista: a degradação do trabalho no século XX. Traduzido por Monthly Review Press. Rio de Janeiro: Zahar, 1980.

CARBALLEDA, A. J. M. Ensayo sobre la cuestión social. PROSPECTIVA: Revista de Trabajo Social e Intervención Social, [s.I.], p. 13-28, jan. 2019. Disponível em: http://revistaprospectiva.univalle.edu.co/index.php/prospectiva/article/view/7271. Acesso em: 20 jan. 2019. https://doi.org/10.25100/prts.v0i27.7271

CARDOSO JR, J. C.; JACCOUD, L. Políticas Sociais no Brasil: organização, abrangência e tensões da ação estatal. In: JACCOUD, Luciana (org.). Questão Social e Políticas Sociais no Brasil Contemporâneo. Brasília, DF: IPEA, 2005.

CFESS. Relatório de Deliberações do XXIX Encontro Nacional CFESS/CRESS. Maceió: CFESS, 2000.

CFESS. Relatório de Deliberações do XXX Encontro Nacional CFESS/CRESS. Belo Horizonte: CFESS, 2001.

COUTINHO, C. N. Representação de interesses: formulação de política e hegemonia. In: TEIXEIRA, Sonia Fleury (coord.). Reforma sanitária: em busca de uma teoria. São Paulo: Cortez, 1989. p. 47-60.

DEGENSZAJN, R. R. Polêmicas teóricas na análise marxiana do trabalho no Serviço Social. Revista em Pauta: Teoria Social e Realidade Contemporânea, [s. I.], v. 16, n. 41, p. 154-170, jan./jun. 2018. Disponível em: https://www.epublicacoes.uerj.br/ index.php/revistaempauta/article/view/36691. Acesso em 12 dez. 2018. https://doi.org/10.12957/rep.2018.36691

IAMAMOTO, M. V. O Serviço Social na contemporaneidade: trabalho e formação profissional. 10. ed. São Paulo: Cortez, 2006.

IAMAMOTO, M. V. Serviço Social, questão social e trabalho em tempo de capital fetiche. In: RAICHELIS et al. (org.). A nova morfologia do trabalho no Serviço Social. São Paulo: Cortez, 2018.

IAMAMOTO, M. V. Atribuições Privativas do(a) Assistente Social em debate. Brasília, DF: CFESS, 2002.

KAMEYAMA, N. As novas tendências das políticas sociais. In: ENPESS, 9., 2000, Brasília. [S. I.: s. n.]: 2000.

KOIKE, M. dos S. et al. Caracterização da área de Serviço Social. Formação Profissional: Trajetórias e Desafios. Caderno Abess, São Paulo, n. 7, 1997. Disponível em: http://www.abepss.org.br/revista-temporalis/edicoes-anteriores/formacaoprofissional-trajetorias-e-desafios-caderno-abess-n7-cortez-sao-paulo-1997-14. Acesso em: 10 dez. 2019.

MANDEL. E. O Capitalismo Tardio. Tradução de Carlos Eduardo Silveira Matos, Regis de Castro Andrade e Dinah de Abreu Azevedo. São Paulo: Abril Cultural, 1982.

NETTO, J. P. A construção do projeto ético-político do Serviço Social. In: MOTA, E. et al. Serviço Social e Saúde: formação e trabalho profissional. São Paulo: Cortez, 2006.

NETTO, J. P.; BRAZ, M. Economia política: uma introdução crítica. São Paulo: Cortez, 2006.

SILVA, M. O. da S.; YAZBEK, M. C.; DI GIOVANNI, G. A Política Social Brasileira no Século XXI. A prevalência dos programas de transferência de renda. São Paulo. Cortez, 2004.

SIMIONATTO, I. As políticas sociais no capitalismo contemporâneo. In: SEMINÁRIO DO PROCAD, 1., 2008, Porto Alegre. (Palestra).

SOUZA, R. B.; AZEREDO, V. G. O assistente social e a ação competente: a dinâmica cotidiana. Serviço Social \& Sociedade, São Paulo, ano 15, n. 80, p. 48-58, nov. 2004.

WERNECK VIANNA, M. L. T. A nova Política Social no Brasil: uma prática acima de qualquer suspeita teórica? Revista Praia Vermelha: estudos de política e teórica social, Rio de Janeiro, Programa de Pós-graduação em Serviço Social da Universidade Federal do Rio de Janeiro, v. 18, n. 1, 2008.

YAZBEK, M. C. Estado e Políticas Sociais. Revista Praia Vermelha: estudos de política e teórica social, Rio de Janeiro, Programa de Pós-graduação em Serviço Social da Universidade Federal do Rio de Janeiro, v. 18, n. 1, 2008. 


\section{Notas}

1 Projeto apoiado com recursos da Fundação de Amparo à Pesquisa do Estado do Rio de Janeiro (FAPERJ).

2 O documento foi apresentado no XXX Encontro Nacional CFESS/CRESS (IAMAMOTO, 2002).

3 Para Carlos Nelson Coutinho (1989), é importante observar que o Estado continua a ser capitalista, por mais "ampliado" que seja, por mais que represente interesses plurais, sempre que - baseado em seus critérios de seletividade - atuar no sentido da manutenção de uma esfera econômica "privada", fora do alcance da esfera política. É essa separação última entre economia e política que caracteriza a natureza capitalista do Estado moderno. Com isso, o pressuposto de que, em um sistema hegemônico, o Estado capitalista tem de fazer concessões, qual é o limite para tais concessões? Ou qual é o limite para a expansão de políticas sociais no interior da sociedade capitalista? O autor faz, portanto, uma analogia com a teoria marxista do salário. Assim, para Marx, a fixação do salário oscila entre dois limites: um limite mínimo, que seria estabelecido pela garantia da reprodução biológica do trabalhador, e um limite máximo, determinado pela possibilidade de lucro para quem compra a força de trabalho, ou seja, pela conservação de uma taxa de acumulação que assegure a reprodução ampliada do capital.

${ }^{4}$ Segundo Mandel (1982), no capitalismo não existe equilíbrio. A busca por superlucros apresenta, como consequência, a impossibilidade de nivelamento da taxa de lucros. Dessa maneira, é próprio do sistema a desigualdade. A pauperização da classe subalterna é reafirmada com o exército industrial de reserva e a tendência decrescente da taxa de lucro. Marx, por sua vez, diz que o capitalismo inevitavelmente cria e mantém uma reserva de força de trabalho desempregada e parcialmente empregada, impedindo, assim, que o salário real aumente de maneira mais rápida do que a produtividade do trabalho. Evidentemente, a perpetuação dessa pressão é dada pela detenção da propriedade privada e dos meios de produção.

${ }^{5}$ A Cepal, em suas formulações sobre desenvolvimento econômico, levantou a hipótese de que o plano das transformações do Brasil em médio e longo prazo, pauta-se no equilíbrio entre neoliberalismo e neodesenvolvimentismo. Assim, Bielschowsky (2009) aponta que no Brasil existem estratégias de transformação econômica e social, por meio da elevação produtiva, situando as reformas de segunda geração: inovação e competitividade; crescimento com redistribuição, via consumo de massa; integração territorial; combate à pobreza e à concentração da renda; preservação ambiental. O cerne da proposta cepalina associa o consumo à cidadania, constituindo a realização da cidadania pelo consumidor. Tal estratégia de crescimento percebe o aumento da demanda real, ao transferir renda para as famílias pobres. Dessa forma, há a ampliação do consumo, logo da produção, tendo como resultado a geração de empregos e o crescimento econômico.

Recebido em: 06/06/2019.

Aprovado em: 02/12/2019.

Publicado em: 30/01/2020

\section{Correspondência para:}

Universidade Federal Fluminense (UFF)

Rua José do Patrocínio - Centro

28010-385, Campos dos Goytacazes, RJ, Brasil

Autor:

VALTER MARTins

Doutor em Serviço Social pela Pontifícia Universidade Católica de São Paulo (PUC-SP). Professor do Departamento de Serviço Social da Universidade Federal Fluminense (UFF).

Orcid: http://orcid.org/0000-0002-7953-0789

E-mail: valter.martins@gmail.com 